\title{
Reduction of ferrihydrite with adsorbed and coprecipitated organic matter: microbial reduction by Geobacter bremensis vs. abiotic reduction by Na-dithionite
}

\author{
K. Eusterhues ${ }^{1}$, A. Hädrich ${ }^{2}$, J. Neidhardt ${ }^{1}$, K. Küsel ${ }^{2,3}$, T. F. Keller ${ }^{4,}{ }^{*}$, K. D. Jandt ${ }^{4}$, and K. U. Totsche ${ }^{1}$ \\ ${ }^{1}$ Institut für Geowissenschaften, Friedrich-Schiller-Universität Jena, 07749 Jena, Germany \\ ${ }^{2}$ Institut für Ökologie, Friedrich-Schiller-Universität Jena, 07743 Jena, Germany \\ ${ }^{3}$ German Centre for Integrative Biodiversity Research (iDiv) Halle-Jena-Leipzig, 04103 Leipzig, Germany \\ ${ }^{4}$ Chair of Materials Science, Otto Schott Institute of Materials Research, Faculty of Physics and Astronomy, \\ Friedrich-Schiller-University Jena, 07743 Jena, Germany \\ *now at: Deutsches Elektronen-Synchrotron DESY, 22607 Hamburg, Germany
}

Correspondence to: K. Eusterhues (karin.eusterhues@uni-jena.de)

Received: 20 February 2014 - Published in Biogeosciences Discuss.: 28 April 2014

Revised: 28 July 2014 - Accepted: 14 August 2014 - Published: 16 September 2014

\begin{abstract}
Ferrihydrite is a widespread poorly crystalline Fe oxide which becomes easily coated by natural organic matter in the environment. This mineral-bound organic matter entirely changes the mineral surface properties and therefore the reactivity of the original mineral. Here, we investigated 2-line ferrihydrite, ferrihydrite with adsorbed organic matter, and ferrihydrite coprecipitated with organic matter for microbial and abiotic reduction of Fe(III). Ferrihydrite-organic matter associations with different organic matter loadings were reduced either by Geobacter bremensis or abiotically by Na-dithionite. Both types of experiments showed decreasing initial Fe-reduction rates and decreasing degrees of reduction with increasing amounts of mineral-bound organic matter. At similar organic matter loadings, coprecipitated ferrihydrites were more reactive than ferrihydrites with adsorbed organic matter. The difference can be explained by the smaller crystal size and poor crystallinity of such coprecipitates. At small organic matter loadings the poor crystallinity of coprecipitates led to even faster Fe-reduction rates than found for pure ferrihydrite. The amount of mineral-bound organic matter also affected the formation of secondary minerals: goethite was only found after reduction of organic matter-free ferrihydrite and siderite was only detected when ferrihydrites with relatively low amounts of mineral-bound organic matter were reduced. We conclude that direct contact of $G$. bremensis to the Fe oxide mineral surface was inhibited
\end{abstract}

by attached organic matter. Consequently, mineral-bound organic matter shall be taken into account as a factor in slowing down reductive dissolution.

\section{Introduction}

Natural Fe oxides are typically nanoparticles and contribute significantly to the total surface area and reactivity of a soil (Karltun et al., 2000; van der Zee et al., 2003; Eusterhues et al., 2005; Regelink et al., 2013). Due to their high reactivity towards dissolved organic matter (Torn et al., 1997; Kaiser and Zech, 2000), Fe oxides are partially or completely covered by organic matter in natural environments. Organic coverage may result in surfaces properties strongly different from those of the original oxides, with consequences for aggregation, mobility, and solubility.

One of the most common Fe oxides is poorly crystalline ferrihydrite, usually forming aggregates of nanometer-sized individual crystals (Jambor and Dutrizac, 1998; Bigham et al., 2002; Cornell and Schwertmann, 2003). In contrast to adsorption of organic matter on pre-existing ferrihydrite surfaces, coprecipitation leads to adsorption and occlusion (physical entrapment) of organic molecules in the interstices between the ferrihydrite crystals. Additionally, the presence of dissolved organic matter inhibits ferrihydrite growth 
(Schwertmann et al., 2005; Mikutta et al., 2008; Eusterhues et al., 2008; Cismasu et al., 2011), and so coprecipitated ferrihydrites tend to develop smaller crystal sizes and more crystallographic defects. Likewise, the aggregation behavior of ferrihydrites may be affected. Since ferrihydrite is often formed in organic matter-rich solutions, e.g., in sediments and soils, we assume that coprecipitation is a common process in nature. As coprecipitated ferrihydrites differ in many properties from pure ferrihydrites, we suppose that the accessibility and solubility of ferrihydrite surfaces as well as the accessibility of the adsorbed/occluded organic matter to microorganisms, extracellular enzymes, redox active shuttling compounds, or reducing agents may differ from ferrihydrites with purely adsorbed organic matter.

In the past, dissolved humic acids from alkaline extracts have been added to microbial experiments to test their influence on ferric iron reduction. It was suggested that they may enhance $\mathrm{Fe}(\mathrm{III})$ reduction by electron shuttling (Lovley et al., 1996; Hansel et al., 2004; Jiang and Kappler, 2008; Roden et al., 2010), complexation of Fe(II) (Royer et al., 2002), or complexation and dissolution of Fe(III) (Jones et al., 2009). Amstaetter et al. (2012) and Jiang and Kappler (2008) observed that the concentration of humic acid or the mineral/humic acid ratio may control whether humic acids increase reduction or not. At high ferrihydrite concentrations in solution ( $30 \mathrm{mM})$, Amstaetter et al. (2012) even observed a decrease in $\mathrm{Fe}$ (III) reduction due to humic acid addition. The decrease was explained by an increased aggregation and a therefore reduced accessibility of the Fe oxide surface for bacteria. The influence of mineral-bound organic matter on reduction and mineral transformation is less well investigated. We are aware of only three articles: Henneberry et al. (2012) coprecipitated ferrihydrite with dissolved organic matter from an agricultural drain and exposed the products to $\mathrm{S}(-\mathrm{II})$ and $\mathrm{Fe}(\mathrm{II})$. Neither a release of the mineralassociated organic matter nor a mineral transformation was observed during reduction. Pédrot et al. (2011) produced nanometer-sized lepidocrocite and Fe-humic acid coprecipitates and compared its reduction by Shewanella putrefaciens. They found the reduction of the coprecipitates to be about eight times faster than that of pure lepidocrocite. Shimizu et al. (2013) studied the influence of coprecipitated humic acid on ferrihydrite reduction by Shewanella putrefaciens strain $\mathrm{CN} 32$. Low $\mathrm{C} / \mathrm{Fe}$ ratios were reported to decrease the reduction of the ferrihydrite-humic acid associations, whereas an increased reactivity was found at high $\mathrm{C} / \mathrm{Fe}$ ratios. In addition, the mineral-bound humic acid changed the mineral transformation during reduction. The formation of goethite was inhibited, the formation of magnetite decreased, and the formation of a green rust-like phase stimulated (Shimizu et al., 2013). Such changes in the mineral assemblage will strongly affect the cycling of Fe.

Our study aims to enlighten changes in microbial and abiotic $\mathrm{Fe}$ (III) reduction caused by mineral-bound organic matter. A water extract of a Podzol forest floor was used as or- ganic matter and served to represent dissolved soil organic matter. We produced ferrihydrites with different organic matter loadings by adsorption and coprecipitation, which were then exposed to microbial reduction by Geobacter bremensis and chemical reduction by Na-dithionite. Geobacter bremensis is common in soil and serves as a well-investigated model organism for dissimilatory Fe(III) reduction. Main objectives were to find out whether mineral-bound organic matter increases or decreases ferrihydrite reactivity and whether coprecipitates differ in reactivity from ferrihydrites with adsorbed organic matter. The formation of secondary minerals was followed by X-ray diffraction (XRD).

\section{Methods}

\subsection{Materials}

All chemicals used in this study were reagent grade. For preparation of stock solution and media, $18 \mathrm{M} \Omega$ doubly deionized water was used. Geobacter bremensis (DSM 12179; Straub and Buchholz-Cleven, 2001) was obtained from the German Resource Centre for Biological Material (DSMZ, Braunschweig).

\subsection{Extraction of soil organic matter}

A forest-floor extract was obtained from the $\mathrm{Oa}$ and Oe layers of a Podzol under spruce close to Freising, Germany. These layers represent the fermented and humified organic horizons below the fresh plant litter, but above the mineral soil. The forest-floor samples were air-dried and passed through a $2 \mathrm{~mm}$ sieve to remove coarse plant remnants. Aliquots of $150 \mathrm{~g}$ soil and $700 \mathrm{~mL}$ deionized $\mathrm{H}_{2} \mathrm{O}$ were shaken end-overend for $16 \mathrm{~h}$ at room temperature and then centrifuged. The supernatant was pressure-filtered through polyvinylidene fluoride (Durapore; $0.45 \mu \mathrm{m}$ pore width) membranes, concentrated in low-temperature rotary evaporators and freezedried. The $\mathrm{C}$ and $\mathrm{N}$ concentration of the forest-floor extract was measured using a CN analyzer (Vario EL, Elementar Analysensysteme, Hanau, Germany). A transmission Fourier transform infrared spectroscopy (FTIR) spectrum was collected using the Nicolet iS10 (Thermo Fisher Scientific, Dreieich, Germany; see below). A solid-state ${ }^{13} \mathrm{C}$ NMR (nuclear magnetic resonance) spectrum was acquired with a Bruker DSX-200 NMR spectrometer (Bruker BioSpin, Karlsruhe, Germany), applying cross-polarization with magic angle spinning (CP MAS) at a spinning frequency of $6.8 \mathrm{kHz}$ and a contact time of $1 \mathrm{~ms}$. A ramped ${ }^{1} \mathrm{H}$ pulse was used during contact time to circumvent spin modulation of Hartmann-Hahn conditions. Pulse delays between 200 and $2000 \mathrm{~ms}$ were chosen. 


\subsection{Synthesis of ferrihydrite and ferrihydrite-organic matter associations}

A 2-line ferrihydrite was produced by titrating a $0.01 \mathrm{M}$ $\mathrm{Fe}\left(\mathrm{NO}_{3}\right)_{3}$ solution with $0.1 \mathrm{M} \mathrm{NaOH}$ to $\mathrm{pH} 5$ under vigorous stirring. A series of ferrihydrites with different amounts of adsorbed organic matter were produced by mixing forestfloor extract solutions of different $\mathrm{C}$ concentrations with suspensions of freshly precipitated 2-line ferrihydrite at $\mathrm{pH} 5$. The molar $\mathrm{C} / \mathrm{Fe}$ ratio of the initial solutions was AFhA 0.4, $\mathrm{AFhB} 1.3$, and AFhD 4.2. Coprecipitated ferrihydrites were obtained by dissolving $\mathrm{Fe}\left(\mathrm{NO}_{3}\right)_{3}$ in forest-floor extract solutions of different concentrations and adding $0.1 \mathrm{M} \mathrm{NaOH}$ under vigorous stirring until a $\mathrm{pH}$ of 5 was reached. The molar $\mathrm{C} / \mathrm{Fe}$ ratio of these initial solutions was $\mathrm{CFhA} 0.4$, $\mathrm{CFhB} 1.3$, and CFhD 4.2. The solid / solution (g/L) ratio varied between 0.3 and 1.6 for all syntheses. The solid products were separated by centrifugation, washed twice with deionized $\mathrm{H}_{2} \mathrm{O}$ and freeze-dried. The $\mathrm{C}$ concentration of these samples was analyzed with the $\mathrm{CN}$ analyzer (Vario EL, Elementar Analysensysteme, Hanau, Germany). Transmission FTIR spectra were taken (Nicolet iS10, Thermo Fisher Scientific, Dreieich, Germany) on pellets of $2 \mathrm{mg}$ sample diluted with $200 \mathrm{mg} \mathrm{KBr}$ between 4000 and $400 \mathrm{~cm}^{-1}$, accumulating 32 scans at a resolution of $4 \mathrm{~cm}^{-1}$. The spectra were baseline corrected by subtracting a straight line running between the two minima of each spectrum and normalized by dividing each data point by the spectrums maximum. The second derivative was calculated using the Savitzky-Golay algorithm over 19-23 points. The specific surface area of the pure ferrihydrite was measured by $\mathrm{N}_{2}$ gas adsorption (Autosorb1, Quantachrome, Odelzhausen, Germany) and calculated according to the BET- equation from 11 data points in the relative pressure range of 0.05 to 0.3 . Prior to the measurements the sample was outgassed for at least $16 \mathrm{~h}$ at $343 \mathrm{~K}$ in vacuum to remove adsorbed water from the sample surfaces. X-ray photoelectron spectra (XPS) were recorded using a Quantum 2000 (PHI Co., Chanhassen, MN, USA) instrument with a focused monochromatic $\mathrm{Al}_{\mathrm{K} \alpha}$ source $(1486.7 \mathrm{eV})$ for excitation. For the high-resolution spectra, the pass energy was set to $58.70 \mathrm{eV}$. After subtracting a Shirley-type background, $\mathrm{P} 2 \mathrm{p}$ and N1s spectra were evaluated by fitting single pseudoVoigt profiles (Lorentz portion $=0.2$ ) to the measured data. Fe2p spectra were fitted by a pre-peak, a surface peak, and four multiplet peaks of decreasing intensity as proposed by McIntyre and Zetaruk (1977) and Grosvenor et al. (2004) for high-spin Fe(III) compounds. Distances between multiplets were constrained to $1 \mathrm{eV}$, the FWHM was set to $1.4 \mathrm{eV}$, and the Lorentz portion of the pseudo-Voigt curves was 0.2. The $\mathrm{C} 1 \mathrm{~s}$ peak was fitted using four pseudo-Voigt profiles with a fixed FWHM of 1.9 and a Lorentz portion of 0.2. The distances between the peaks were fixed to $1.6,1.6$, and $1.1 \mathrm{eV}$ from lower to higher binding energies to distinguish the $\mathrm{C} 1 \mathrm{~s}$ binding states $\mathrm{C}-\mathrm{C}$ and $\mathrm{C}-\mathrm{H}, \mathrm{C}-\mathrm{O}$ and $\mathrm{C}-\mathrm{N}, \mathrm{C}=\mathrm{O}$ and $\mathrm{N}-$ $\mathrm{C}=\mathrm{O}$, and $\mathrm{O}-\mathrm{C}=\mathrm{O}$.

\subsection{Microbial reduction experiments}

Differences in reducibility of ferrihydrite and ferrihydriteorganic matter associations and secondary mineralization were studied in liquid cultures inoculated with G. bremensis. A defined freshwater medium based on the Geobacter medium ATCC 1957, containing $1.5 \mathrm{~g} \mathrm{~L}^{-1} \mathrm{NH}_{4} \mathrm{Cl}$ and $0.1 \mathrm{~g} \mathrm{~L}^{-1} \mathrm{KCl}$, was used. After autoclaving and cooling under an $\mathrm{N}_{2} / \mathrm{CO}_{2}(80 / 20 v / v)$ atmosphere, $30 \mathrm{~mL} \mathrm{~L}^{-1}$ of $1 \mathrm{M}$ $\mathrm{NaHCO}_{3}$ (autoclaved, $\mathrm{CO}_{2}$ ), $10 \mathrm{~mL} \mathrm{~L}^{-1}$ Wolfe's vitamin solution (ATCC 1957), $10 \mathrm{~mL} \mathrm{~L}^{-1}$ modified Wolfe's minerals (ATCC, 1957), and sodium-acetate (7 mM) as carbon source were added. Unless stated otherwise, added solutions were prepared under anoxic $\left(\mathrm{N}_{2}\right)$ conditions and filter sterilized $(0.2 \mu \mathrm{m}, \mathrm{PVDF}) . \mathrm{NaH}_{2} \mathrm{PO}_{4}$ from the original recipe was not added to avoid interaction of $\mathrm{PO}_{4}^{3-}$ with ferrihydrite. The final medium had a $\mathrm{pH}$ of 6.8 . The $\mathrm{pH}$ was chosen because recommended for optimum growth of Geobacter, by both the DSMZ (medium 579, pH 6.7 to 7.0) as well as the ATCC (medium 1957, pH 6.8). Adsorption and coprecipitation experiments were performed at $\mathrm{pH} 5$, i.e., under $\mathrm{pH}$ conditions where most coprecipitates form in the presence of dissolved organic matter (Eusterhues et al., 2011). However, the higher $\mathrm{pH}$ during reduction experiments may have caused desorption of some of the mineral-bound organic matter.

The medium $(10 \mathrm{~mL})$ was dispensed under an $\mathrm{N}_{2}$ gas stream into pre-sterilized $\left(6 \mathrm{~h} 180^{\circ} \mathrm{C}\right) 21 \mathrm{~mL}$-culture tubes that contained pre-weighed ferrihydrite and ferrihydriteorganic matter associations ( $40 \mathrm{mM}$ Fe per tube). After tubes were closed with butyl rubber stoppers and capped with aluminum rings, they were flushed again with sterile $\mathrm{N}_{2} / \mathrm{CO}_{2}$ $(80 / 20 v / v)$, applying an overpressure of $\sim 100$ mbar. Pressure was monitored with a needle tensiometer (TensioCheck TC1066, Tensiotechnik). Inoculation of ferrihydrite and ferrihydrite-organic matter associations was performed with $4.8 \%\left(v / v\right.$; initial cell density $\left.\sim 10^{8} \mathrm{~mL}^{-1}\right)$ G. bremensis pre-culture grown on phosphate-free medium with sodiumfumarate $(50 \mathrm{mM})$ as electron acceptor and sodium-acetate $(20 \mathrm{mM})$ as electron donor and carbon source. Triplicate samples of all treatments were incubated horizontally $\left(30^{\circ} \mathrm{C}\right)$ in the dark and shaken periodically.

For Fe(II) determination, $0.2 \mathrm{~mL}$ subsamples were taken anoxically from well shaken culture tubes with a syringe and transferred into $0.5 \mathrm{M} \mathrm{HCl}$ for extraction ( $1 \mathrm{~h}$ in the dark). $\mathrm{Fe}$ (II) of the extraction solutions was determined using the phenanthroline assay (Tamura et al., 1974). Fe(total) was analyzed via ICP-OES (Spectroflame, Spectro, Kleve, Germany). Solid remnants of the incubation experiments were freeze dried and stored under $\mathrm{N}_{2}$ until X-ray diffraction measurements (D8 Advance DaVinci diffractometer by Bruker AXS, Karlsruhe, Germany) were performed using $\mathrm{Cu}-\mathrm{K} \alpha$ radiation at $40 \mathrm{kV}$ and $40 \mathrm{~mA}$. 


\subsection{Abiotic reduction experiments with Na-dithionite}

Chemical reducibility of ferrihydrite and ferrihydrite-organic matter associations was evaluated in abiotic reduction experiments performed after Houben (2003). In short, ferrihydrite and ferrihydrite-organic matter associations (ca. $0.1 \mathrm{mmol} \mathrm{Fe}$ in ferrihydrite) were added to $0.5 \mathrm{~L}$ of anoxic $\left(\mathrm{N}_{2}\right)$ $0.01 \mathrm{MNa}$-dithionite solution buffered with ca. $0.015 \mathrm{M}$ $\mathrm{NaHCO}_{3}$ in a $1 \mathrm{~L}$ screw cap bottle. Bottles were closed immediately with a rubber stopper and a metal screw cab, shaken thoroughly and afterwards stirred constantly at room temperature. The solution $\mathrm{pH}$ was adjusted to $\sim 7$ before ferrihydrite addition by shortly purging with $\mathrm{CO}_{2}$ and was stable during the experiment. Periodically, samples of $0.5 \mathrm{~mL}$ were taken with $\mathrm{N}_{2}$ flushed syringes and filtered through $0.2 \mu \mathrm{m}$ membranes (PVDF) into cuvettes filled with $0.5 \mathrm{~mL}$ acetate (to quench the reduction) and $\mathrm{ddH}_{2} \mathrm{O}$ (for dilution). The dissolved Fe(II) was measured using the phenantroline method (Tamura et al., 1974).

\subsection{Evaluation of reduction rates}

$\mathrm{Fe}(\mathrm{II})$ formation kinetics were used as analogues for $\mathrm{Fe}(\mathrm{III})$ reduction. Apparent initial reaction rates were estimated by fitting linear regression lines to $\mathrm{Fe}$ (II) / Fe(total) versus time for the first data points acquired in microbial and abiotic reduction experiments. The slope of the line represents the initial reaction rate. The degree of dissolution was determined at day 17 for microbial experiments and after $75 \mathrm{~min}$ for abiotic experiments. Day 17 for microbial experiments was chosen because the $\mathrm{Fe}$ (II) / Fe(total) of the ferrihydrite control at day 52 is much lower than at day 17 and therefore probably wrong. We assume that this is due to unintentional oxidation at the end of the experiment in this sample. The data were fit also to a model proposed first by Christoffersen and Christoffersen (1976) and used successfully by, e.g., Postma (1993), Larsen and Postma (2001), Houben (2003), and Roden (2004):

$m_{t} / m_{0}=[-k(1-\gamma) t+1]^{1 /(1-\gamma)}$

where $m_{0}$ is the initial concentration of Fe(III), $m_{t}$ the concentration of $\mathrm{Fe}(\mathrm{II})$ at time $t, k$ the rate constant, and $\gamma$ a constant describing the Fe mineral reactivity as controlled by crystal size, morphology, structure, and available reactive surface sites (Postma, 1993; Roden, 2004). While we were successful in fitting the abiotic variants, the model failed to reconstruct the biotic dissolution variants (data not shown). This may point to other processes involved in the biotic dissolution, e.g., a preferential selection of a size fraction of the ferrihydrite-organic matter-associations. However, the comparably poor data quality of the biotic variants does not allow for an in-depth interpretation of this finding.

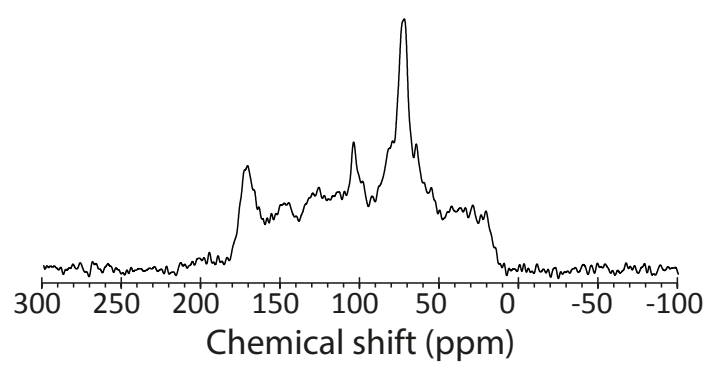

Figure 1. ${ }^{13} \mathrm{C}$ Cross-polarization magic angle spinning nuclear magnetic resonance spectrum $\left({ }^{13} \mathrm{C}\right.$ CPMAS NMR $)$ of the forestfloor extract.

\section{Results and discussion}

\subsection{Characterization of forest-floor extract, control ferrihydrite, and ferrihydrite-organic matter associations}

The forest-floor extract for the production of ferrihydriteorganic matter associations was characterized by its $\mathrm{C} / \mathrm{N}$ ratio, solid state ${ }^{13} \mathrm{C}$ NMR (Fig. 1), and FTIR (Fig. 2). The concentrations of $\mathrm{C}$ and $\mathrm{N}$ were found to be $35.1 \%$ and $4.3 \%$. Organic $\mathrm{C}$ in the respective chemical shift regions of the NMR spectrum was quantified to $13 \%$ of total organic carbon (TOC) alkyl C (0-45 ppm), 51\% of TOC O-alkyl C (45-110 ppm), $24 \%$ of TOC aryl C (110-160 ppm), and $13 \%$ of TOC carbonyl C (160-220 ppm). In comparison to the material used for previous adsorption and coprecipitation studies (Eusterhues et al., 2008; Eusterhues et al., 2011; Eusterhues et al., 2014), this material had a higher content in aromatic groups and carbonyl $\mathrm{C}$ (ester, carboxyl, or amide groups), and less carbohydrates. The FTIR spectrum (Fig. 2; band assignment according to Abdulla et al., 2010) shows strong peaks at $1722 \mathrm{~cm}^{-1}(\mathrm{C}=\mathrm{O}$ of $\mathrm{COOH}), 1622 \mathrm{~cm}^{-1}$ (complexed $\left.\mathrm{COO}^{-}\right)$, and at 1148, 1089, and $1041 \mathrm{~cm}^{-1}(\mathrm{C}-\mathrm{O}$ in carbohydrates). Very sharp signals at 1384 and $825 \mathrm{~cm}^{-1}$ are caused by $\mathrm{NO}_{3}^{-}$, and show that only part of the $\mathrm{N}$ can belong to amides. Additional smaller signals can be identified using the second derivative of the spectrum: the signal at $1783 \mathrm{~cm}^{-1}$ points to the $\mathrm{C}=\mathrm{O}$ stretching of $\gamma$-lactones, signals at 1547 and $1268 \mathrm{~cm}^{-1}$ can be explained by amide II and amide III, and signals at 1512 and $1218 \mathrm{~cm}^{-1}$ are in accordance with the $\mathrm{C}=\mathrm{C}$ stretching of aromatic rings and with the asymmetric $\mathrm{C}-\mathrm{O}$ stretching of aromatic $\mathrm{OH}$. The signal at $965 \mathrm{~cm}^{-1}$ belongs to the $\mathrm{O}-\mathrm{H}$ out of plane bending of carboxylic acids and the band at $660 \mathrm{~cm}^{-1}$ to the $\mathrm{O}-\mathrm{H}$ out of plane bending of carbohydrates.

The control ferrihydrite as well as the ferrihydrites in coprecipitates and adsorption complexes displayed XRD patterns of a typical 2-line ferrihydrite (Cornell and Schwertmann, 2003). The specific surface area of the control ferrihydrite was $197 \mathrm{~m}^{2} \mathrm{~g}^{-1}$ as determined by $\mathrm{N}_{2}$ gas adsorption and the concentrations of $\mathrm{C}$ and $\mathrm{N}$ were found to 


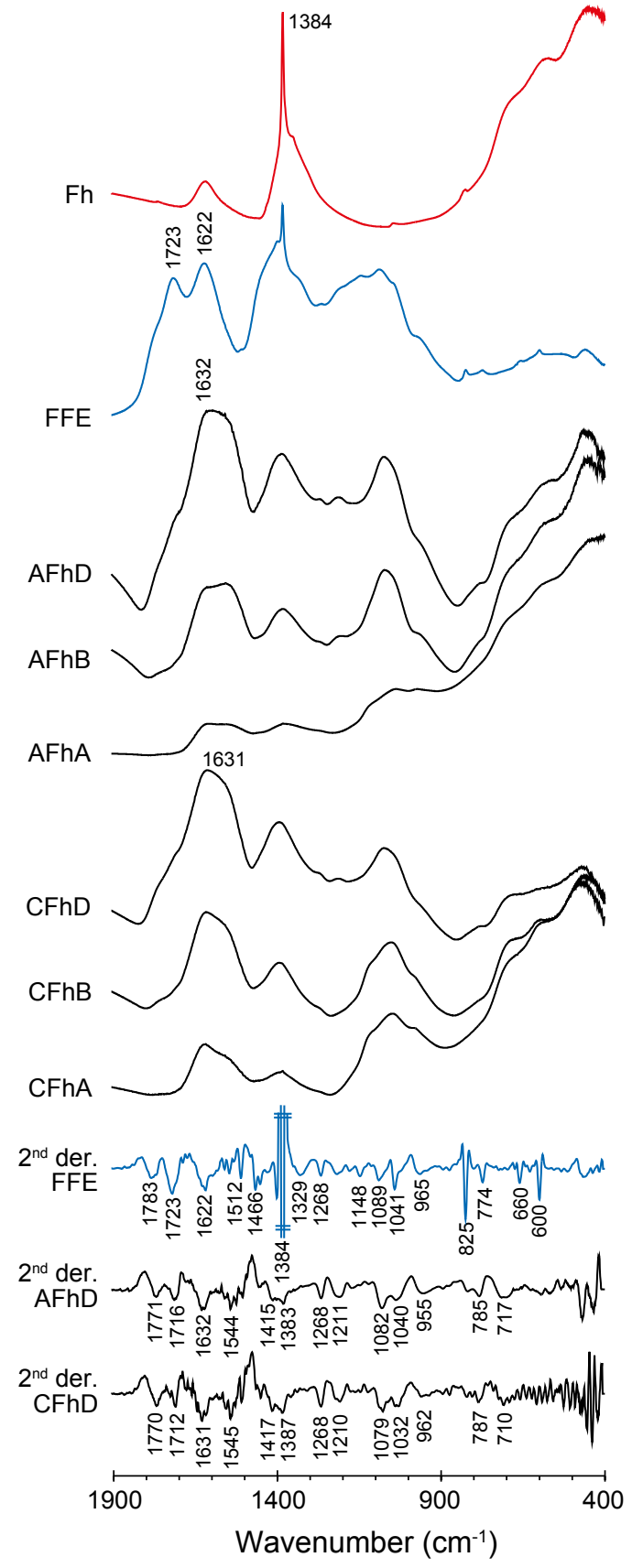

Figure 2. FTIR spectra of the control ferrihydrite (Fh), the original forest-floor extract (FFE), the adsorption complexes ( $\mathrm{AFhD}$, $\mathrm{AFhB}, \mathrm{AFhA}$ ), and the coprecipitates (CFhD, CFhB, CFhA). Second derivatives are given for spectra of the forest-floor extract and the two ferrihydrite-organic matter complexes with the highest $\mathrm{C}$ concentration. Refer to text for abbreviations.

be $0.2 \%$ and $1.3 \%$. The FTIR spectrum (Fig. 2) showed that this high-N concentration is due to nitrate, which has not been fully removed during ferrihydrite synthesis from $\mathrm{Fe}\left(\mathrm{NO}_{3}\right)_{3} \times 9 \mathrm{H}_{2} \mathrm{O}$. We assume that the nitrate contamination does not affect our microbial reduction experiments

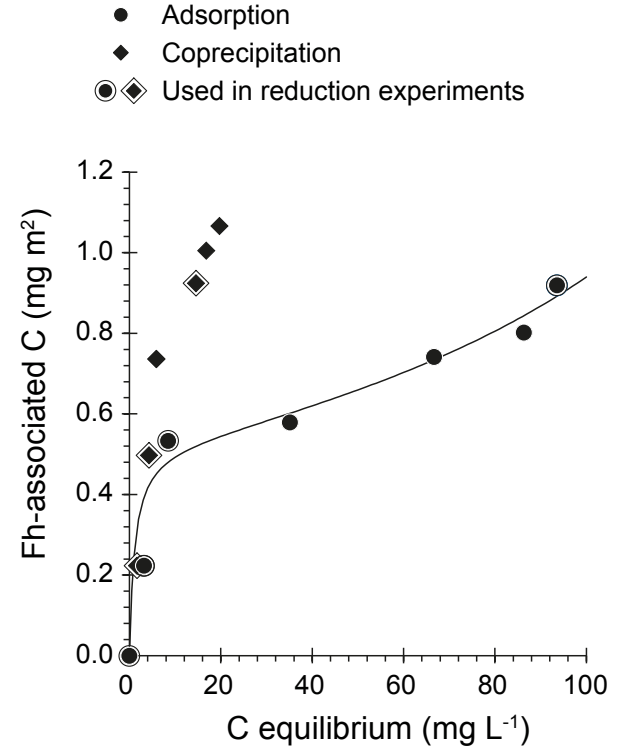

Figure 3. Ferrihydrite-associated $\mathrm{C}$ (normalized to the specific surface area of $197 \mathrm{~m}^{2} \mathrm{~g}^{-1}$ of the control ferrihydrite) vs. C in the equilibrium solution. The line represents a BET isotherm.

because Geobacter bremensis is not able to reduce nitrate (Straub et al., 1998, 2001).

The adsorption isotherm (Fig. 3) can be described by a BET model (Ebadi et al., 2009) with a monolayer adsorption capacity of $q_{\mathrm{m}}=0.52 \mathrm{mg} \mathrm{m}^{-2}$, an equilibrium constant of adsorption for the first layer of $K_{\mathrm{S}}=0.9 \mathrm{~L} \mathrm{mg}^{-1}$, and an equilibrium constant of adsorption for further layers of $K_{\mathrm{L}}=0.0045 \mathrm{~L} \mathrm{mg}^{-1}$. The obtained monolayer loading is in accordance with other adsorption studies involving natural organic matter adsorption and ferrihydrite (Tipping et al., 1981; Kaiser et al., 2007; Eusterhues et al., 2005). Coprecipitation, in contrast, produced considerably larger organic matter loadings of $\sim 1.1 \mathrm{mg} \mathrm{m}^{-2}$. This can be explained either by a larger surface area of coprecipitated ferrihydrites or by the presence of occluded organic matter in addition to adsorbed organic matter in coprecipitates. Such a behavior was previously reported for the coprecipitation of lignin, but not for a forest-floor extract (Eusterhues et al., 2011).

Three samples of each adsorption and the coprecipitation series were selected for the reduction experiments (Table 1).

FTIR-spectra of adsorbed and coprecipitated organic matter differ from the original forest-floor extract. The peak assigned to $\mathrm{C}=\mathrm{O}$ in protonated carboxyl groups $\left(1723 \mathrm{~cm}^{-1}\right)$ is reduced to merely a shoulder (seen only in the second derivative of $\mathrm{AFhD}$ and $\mathrm{CFhD}$ at 1716 and $1712 \mathrm{~cm}^{-1}$ ), while the signal related to deprotonated carboxyl groups $\left(1622 \mathrm{~cm}^{-1}\right.$ in FFE) is increased and shifted to higher wave numbers $\left(1632,1631 \mathrm{~cm}^{-1}\right)$. This pattern is explained by the formation of inner-sphere surface complexes between carboxylic acids and $\mathrm{Fe}$ oxides surfaces or dissolved metals (Kang et al., 2008; Persson and Axe, 2005). The peak at $1148 \mathrm{~cm}^{-1}$ 
Table 1. Carbon concentration and $\mathrm{C} / \mathrm{Fe}$ ratios of ferrihydrite-organic matter associations and results of microbial and abiotic reduction experiments. See text for abbreviations.

\begin{tabular}{|c|c|c|c|c|c|c|c|c|c|c|c|c|}
\hline & & \multirow[b]{3}{*}{$\begin{array}{c}\mathrm{C} \\
\mathrm{mgg}^{-1}\end{array}$} & \multirow[b]{3}{*}{$\begin{array}{c}\mathrm{C} / \mathrm{Fe} \\
\mathrm{mol} \mathrm{mol}^{-1}\end{array}$} & \multicolumn{3}{|c|}{ Reduction by Geobacter bremensis } & \multicolumn{6}{|c|}{ Reduction by Na-dithionite } \\
\hline & & & & \multicolumn{2}{|c|}{ Linear fit } & \multirow[b]{2}{*}{$\begin{array}{c}\text { degree of } \\
\text { dissolution } \%^{\mathrm{a}}\end{array}$} & \multicolumn{2}{|c|}{ Linear fit } & \multirow[b]{2}{*}{$\begin{array}{c}\text { degree of } \\
\text { dissolution } \% \text { b }\end{array}$} & \multicolumn{3}{|c|}{$\mathrm{C}$ and $\mathrm{C}$} \\
\hline & & & & $\begin{array}{c}k \\
\mathrm{~h}^{-1}\end{array}$ & $r^{2}$ & & $\begin{array}{c}k \\
\mathrm{~h}^{-1}\end{array}$ & $r^{2}$ & & $\begin{array}{c}k \\
\mathrm{~h}^{-1}\end{array}$ & $\gamma$ & $r^{2}$ \\
\hline Control & $\mathrm{Fh}$ & - & - & 0.0020 & 0.961 & 63 & 5.29 & 0.998 & 83 & 5.79 & 2.4 & 0.989 \\
\hline Ad- & AFhA & 44 & 0.39 & 0.0017 & 0.955 & 64 & 1.59 & 0.895 & 62 & 2.26 & 2.9 & 0.990 \\
\hline Copreci- & CFhA & 44 & 0.41 & 0.0021 & 0.950 & 82 & $-^{\mathrm{c}}$ & - & - & - & - & - \\
\hline pitated & $\mathrm{CFhB}$ & 98 & 1.06 & 0.0016 & 0.983 & 68 & 1.09 & 0.975 & 64 & 1.32 & 1.9 & 0.995 \\
\hline $\mathrm{OM}$ & $\mathrm{CFhD}$ & 182 & 2.83 & 0.0014 & 0.948 & 41 & 0.18 & 0.975 & 20 & 0.21 & 2.6 & 0.996 \\
\hline
\end{tabular}

a Degree of dissolution at day 17.

b Degree of dissolution at 75 min.

${ }^{c}$ Please note that for the reduction by Na-dithionite for sample CFhA, the dissolved Fe(II) was estimated to be larger than the total Fe, which is not possible;

therefore, we did not calculate reduction rate and degree of reduction for this sample.

(C-O in carbohydrates) in the forest-floor extract is not visible in the adsorbed or coprecipitated organic matter and the peak at $1089 \mathrm{~cm}^{-1}$ is slightly shifted to lower wave numbers $\left(1082,1079 \mathrm{~cm}^{-1}\right)$. Both changes point to a fractionation of carbohydrates during adsorption or coprecipitation. The absence of the sharp peaks at 1384 and $825 \mathrm{~cm}^{-1}$ shows that coprecipitates and adsorption complexes are free of nitrate. We assume, the adsorption of organic matter has removed the surface-bound nitrate, which could not be removed from ferrihydrite through washing (Fh in Fig. 2), and the natural nitrate from the forest-floor extract did not react with the $\mathrm{Fe}$ oxides (FFE in Fig. 2).

FTIR spectra and their second derivatives of adsorbed and coprecipitated organic matter are remarkably similar. Small differences, however, exists for the main carbohydrate peak and its shoulders, but seem mainly related to the amount of mineral-bound organic matter: while carbohydrates are represented by peaks at $\sim 1125, \sim 1080$, and $\sim 1040 \mathrm{~cm}^{-1}$ in samples with small $\mathrm{C}$ concentrations (AFhA; CFhA), samples with large $\mathrm{C}$ concentration show a strong peak at $\sim 1080 \mathrm{~cm}^{-1}$ and a shoulder at $\sim 1040 \mathrm{~cm}^{-1}$ (AFhD, AFhB, CFhD).

The highly surface-sensitive XPS technique provides the chemical composition of typically less than $10 \mathrm{~nm}$ of the sample surface (Seah and Dench, 1979). High-resolution XPS spectra of the C1s, N1s, Fe2p, and P2p lines are given in Fig. 4. Weak S2p signals (data not shown) above the detection limit were found for the forest-floor extract and for coprecipitates and adsorption complexes with low $\mathrm{C}$ concentrations $\left(<115 \mathrm{mg} \mathrm{g}^{-1}\right)$. The absence of $\mathrm{S}$ in complexes with higher organic matter contents may imply that adsorption of the forest-floor organic material outcompetes adsorption of sulfate. The N1s and the $\mathrm{P} 2 \mathrm{p}$ peaks show considerable noise (Fig. 4), which leads to large scatter for $\mathrm{C} / \mathrm{N}$ and $\mathrm{C} / \mathrm{P}$ ra- tios (Fig. 5). Nevertheless, the data show that the $\mathrm{C} / \mathrm{N}$ ratio and the $\mathrm{C} / \mathrm{P}$ ratio of coprecipitates and adsorption complexes are clearly higher than that of the original forest-floor extract. While C / P-ratios for the coprecipitated organic matter are very similar to that of the adsorbed organic matter, a slightly, but significantly higher mean C / N-ratio (40) for the adsorbed organic matter is observed in comparison to a $\mathrm{C} / \mathrm{N}$ of 35 for coprecipitated organic matter $(\alpha=0.05 ; T$ test). The $\mathrm{C} 1 \mathrm{~s}$ peak can be deconvoluted into four peaks as shown exemplary for the forest-floor extract (Fig. 4) and assigned to $285.0 \mathrm{eV}$ : C-C and C-H; $286.6 \mathrm{eV}$ : C-O and C-N; $288.2 \mathrm{eV}: \mathrm{C}=\mathrm{O}$ and $\mathrm{N}-\mathrm{C}=\mathrm{O}$, and $289.3 \mathrm{eV}: \mathrm{O}-\mathrm{C}=\mathrm{O}$ (Arnarson and Keil, 2001). The adsorbed and coprecipitated organic matter was found enriched in aliphatic $\mathrm{C}(\mathrm{C}-\mathrm{C}, \mathrm{C}-\mathrm{H})$ and carboxylic $\mathrm{C}(\mathrm{O}-\mathrm{C}=\mathrm{O})$, but compositional differences between adsorbed and coprecipitated cannot be seen (data not shown).

To find out whether the exposed ferrihydrite surface differs between coprecipitated ferrihydrites and ferrihydrites with adsorbed organic matter, we determined the $\mathrm{C} / \mathrm{Fe}$-ratio (Fig. 5a). Although coprecipitated ferrihydrites might have occluded a major part of the associated organic matter inside their aggregates, the XPS C/Fe-ratio was found to be similar for samples with the same $\mathrm{C}$ concentration. We therefore assume that the accessibility of the ferrihydrite surface for reducing agents or microbial cells is not systematically different in coprecipitates and in ferrihydrites with adsorbed organic matter.

\subsection{Microbial Fe(III) reduction by Geobacter bremensis}

Incubation of ferrihydrite-organic matter associations with G. bremensis (Fig. 6) revealed that reaction rates and degree of reduction varied with the amount of mineralassociated organic matter: Increasing organic matter loadings 

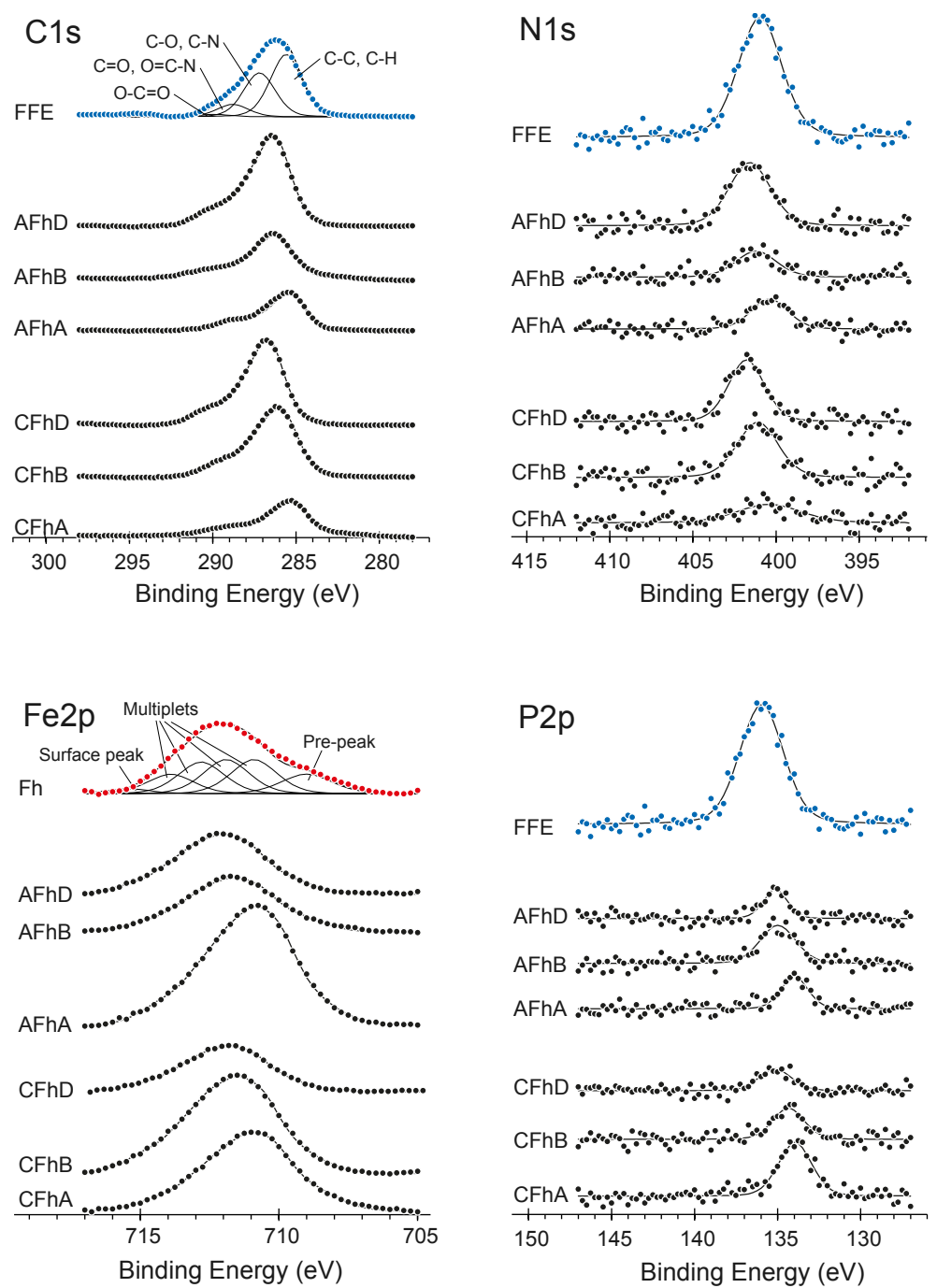

Figure 4. Background corrected XPS spectra of the control ferrihydrite (Fe2p, red), the forest-floor extract (C1s, N1s, P2p, blue), and the incubated coprecipitates and adsorption complexes. Refer to text for abbreviations.

on ferrihydrite led to decreasing initial reaction rates and a decreasing degree of reduction for ferrihydrites with coprecipitated as well as adsorbed organic matter (Table 1). Also, samples of the coprecipitation series were more reactive than samples of the adsorption series, when comparing samples with similar organic matter contents. In case of AFhA, the sample with the smallest amount of adsorbed organic matter $\left(44 \mathrm{mg} \mathrm{g}^{-1} \mathrm{C}\right)$, the initial reaction rate was smaller $\left(0.0017 \mathrm{~min}^{-1}\right)$ than that of the organic matter-free control ferrihydrite Fh $\left(0.0020 \mathrm{~min}^{-1}\right)$, while the degree of dissolution at day 17 was similar (64\%) to that of the control ferrihydrite $(63 \%)$. In case of CFhA, the ferrihydrite sample with the smallest amount of coprecipitated organic matter $\left(44 \mathrm{mg} \mathrm{g}^{-1} \mathrm{C}\right)$, initial reaction rate $\left(0.0021 \mathrm{~min}^{-1}\right)$, and degree of dissolution $(82 \%)$ were even larger than for the control ferrihydrite Fh.
We conclude that the mineral-bound organic matter results in a surface passivation of the ferrihydrite surface. The fact that coprecipitates were more easily reduced than ferrihydrites with adsorbed organic matter may be explained by smaller and more defective individual ferrihydrite crystals in coprecipitates (Eusterhues et al., 2008) and a therefore larger specific surface area. A possibly larger accessible outer ferrihydrite surface in coprecipitates compared to ferrihydrite with the same amount of adsorbed organic matter can be ruled out based on XPS results (Fig. 5a). We assume that these effects dominate over the surface passivation effect due to associated organic matter in case of the fast and extensive reduction of CFhA. A systematically different aggregate structure between ferrihydrite with adsorbed organic matter and coprecipitated ferrihydrites may also have influenced the availability of the mineral surface (Pédrot et al., 2011). A possibly different composition of the mineral-bound organic 

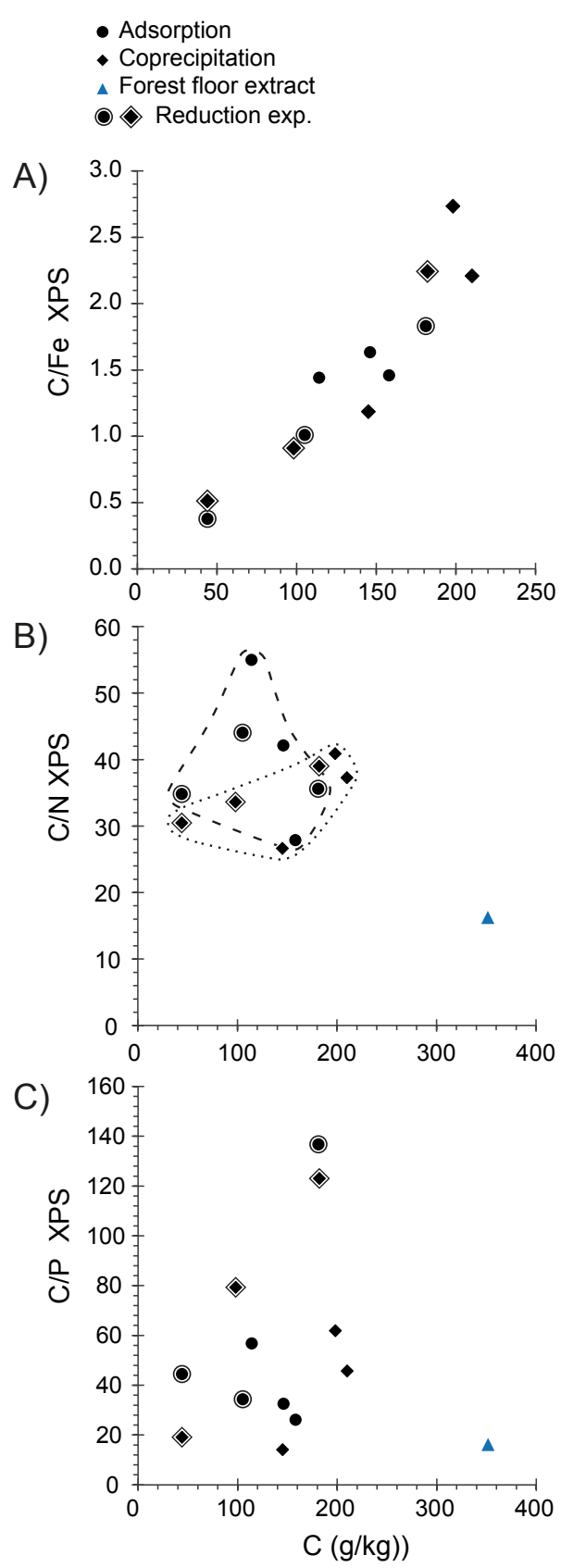

Figure 5. Comparison of chemical surface composition expressed in XPS signal ratios $(\mathrm{C} / \mathrm{Fe}, \mathrm{C} / \mathrm{N}$, and $\mathrm{C} / \mathrm{P})$ and bulk $\mathrm{C}$ content of Fh-OM associations. Dashed and dotted lines in (b) encircle XPS data for adsorption complexes and coprecipitates, respectively, to guide the eye.

matter in coprecipitates compared to adsorption complexes is a further aspect, which has to be taken into account. Although FTIR spectra and XPS spectra were very similar, we cannot exclude differences between adsorbed and coprecipitated material. In a previous experiment with a distinct forest-floor extract (Eusterhues et al., 2011), FTIR spectra had also been very similar, whereas ${ }^{13} \mathrm{C}$ NMR analyses of the non-reacted fraction had shown that the adsorbed organic matter was enriched in O-alkyl C (carbohydrates), but depleted in carbonyl $\mathrm{C}$ and alkyl $\mathrm{C}$ relative to the coprecipitated material. (It was not possible to obtain NMR spectra of reasonable quality of the material used in this study. Formation of soluble Fe complexes in the supernatant might be an explanation.) However, this knowledge does not help us to judge the possibly different efficiency with which the possibly different fractions may inhibit ferrihydrite reduction. The ability of molecules to form bi- or multinuclear inner-sphere bonds was recognized to make strong inhibitors with respect to mineral dissolution (Stumm, 1997), while the presence of electron accepting and electron donating groups in the organic material controls its ability to act as an electron shuttle and promote reduction. Quinones and condensed aromatic groups have been shown to be redox active in humic acids and chars (Dunnivant et al., 1992; Scott et al., 1998; Klüpfel et al., 2014). While we do not expect any condensed aromatics, we cannot quantify quinones or multinuclear inner-sphere bonds in the mineral-bound organic matter.

Our microbial reduction results are surprisingly different from experiments performed by Shimizu et al. (2013), who coprecipitated ferrihydrite with standard humic acids and monitored reduction by Shewanella putrefaciens strain $\mathrm{CN}-32$. They found that increasing amounts of coprecipitated humic acid led to elevated microbial reduction. At high humic acid loadings $(\mathrm{C} / \mathrm{Fe}=4.3)$ reduction rates based on dissolved $\mathrm{Fe}(\mathrm{II})$ were faster than that of pure ferrihydrite, whereas lower humic acid loadings $(\mathrm{C} / \mathrm{Fe}<1.8)$ resulted in slower reduction rates. Pure ferrihydrite was reduced at medium reduction rates. The experiments of Shimizu et al. (2013) are in accordance with the overall assumption that the coprecipitated humic acids are used by Shewanella to transfer electrons from the cell to the Fe oxide and advance its electron shuttling process. A threshold amount of mineral-associated humic acid was assumed to be necessary before electron shuttling accelerates ferrihydrite dissolution (Shimizu et al., 2013).

However, the enhancement of electron shuttling might have been especially strong for the experimental conditions chosen by Shimizu et al. (2013), because the content of aromatic groups and quinones is usually much larger in humic acid than in forest-floor extracts as used in this study. Accordingly, Piepenbrock et al. (2014) could show that the electron accepting capacity, i.e., the concentration of redoxactive functional groups, of a natural forest-floor extract was only half as high as that of the Pahokee Peat Humic Acid.

By comparing the two studies, the question arises if differences in electron transfer mechanisms applied by the $\delta$-Proteobacteria Geobacter and the $\gamma$-Proteobacteria Shewanella can explain whether mineral-bound organic matter increases or decreases the reducibility of Fe oxides. In general, the following electron transfer strategies have been discussed in the literature: (i) direct electron transfer (DET) by either membrane-bound redox enzymes (Nevin and Lovley, 
A) Coprecipitation

$\leadsto$ C Fh A $44 \mathrm{mg} \mathrm{g}^{-1} \mathrm{C}$

$-\rightarrow C$ Fh B $98 \mathrm{mg} \mathrm{g}^{-1} \mathrm{C}$

-. C Fh D $182 \mathrm{mg} \mathrm{g}^{-1} \mathrm{C}$

* Fh control

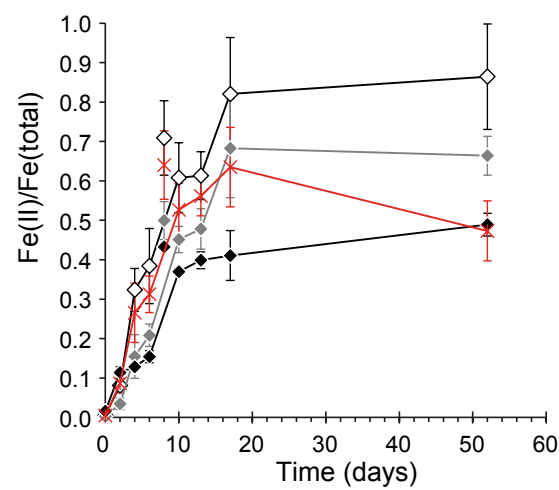

B) Adsorption

$\multimap-A$ Fh A $44 \mathrm{mg} \mathrm{g}^{-1} \mathrm{C}$

- A F F B $105 \mathrm{mg} \mathrm{g}^{-1} \mathrm{C}$

-•-A Fh D $181 \mathrm{mg} \mathrm{g}^{-1} \mathrm{C}$

* Fh control

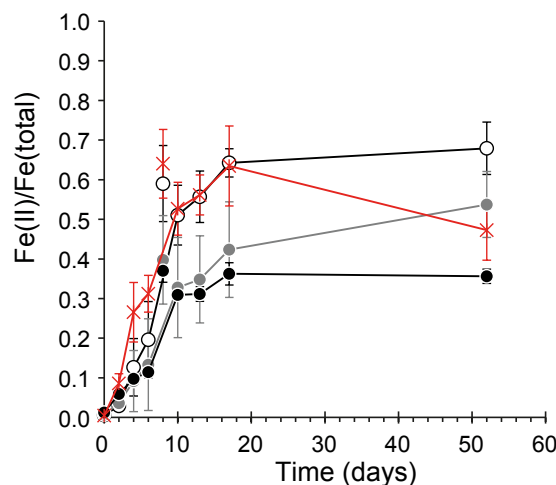

Figure 6. Microbial reduction of ferrihydrite and ferrihydrite-organic matter associations in Geobacter bremensis cultures. The Fe(II) production was normalized to the total initial amount of $\mathrm{Fe}$ in ferrihydrite. The $\mathrm{Fe}(\mathrm{II}) / \mathrm{Fe}$ (total) of the ferrihydrite control (red stars) at day 52 was much lower than at day 17 and therefore unexpectedly low, leading us to assume that this was due to unintentional oxidation at the end of the experiment in this sample (further details see text). Error bars represent standard deviations of triplicate cultures.

2000) or bacterial nanowires (Reguera, et al., 2005; Gorby et al., 2006; Malvankar et al., 2011) and ii) mediated electron transfer (MET) using either chelators (Nevin and Lovley, 2002; Kraemer, 2004) or redox shuttling compounds that are produced by the cell itself (Marsili et al., 2008) or are abundant in the extracellular environment (Lovley et al., 1996). Geobacter has been found to require direct contact to the mineral surface, but is also discussed to use nanowires for electron transfer (Malvankar et al., 2012; Boesen and Nielsen, 2013). Geobacter species can conserve energy from the transfer of electrons to a variety of extracellular electron acceptors including metals like Mn(IV) and U(VI), but also electrodes and humic acids. Shewanella is long known to not rely on direct contact (Arnold et al., 1990; Caccavo et al., 1997; Lies et al., 2005) and to produce chelating compounds like flavins (von Canstein, 2008). A study of Kotloski and Gralnick (2013) recently showed that flavin electron shuttling but not direct electron transfer or nanowires is the primary mechanism of extracellular electron transfer by Shewanella oneidensis.

For Geobacter increasing amounts of mineral-bound organic matter decreased reduction rates and degree of reduction, probably because reactive surface sites of the mineral are blocked by adsorbed organic matter molecules. Additionally, increasing amounts of organic matter will increase the negative charge of the particle surface, which may also impede their accessibility for negatively charged microbial cells (Shimizu et al., 2013 and ref. therein). For Shewanella species, which use chelating agents and electron shuttles, smaller amounts of adsorbed organic matter hinder reduction by passivation of reactive surface sites, whereas large amounts of mineral-bound organic matter can be used to enhance electron shuttling or chelating of Fe. Interestingly, we did not observe such an increase in reduction rates at very large organic matter loadings, although also Geobacter species are able to reduce extracellular organic matter. This can either be explained by the lower concentration of redox active groups in natural dissolved organic matter compared to humic acids (Piepenbrock et al., 2014) or by speciesdependent different capabilities.

Partial reduction of Fe oxides during microbial reduction is explained by surface passivation through adsorption of Fe(II) (Roden and Urrutia, 1999, Liu et al., 2001). Similar to Shimizu et al. (2013) our study shows that mineral-bound organic matter has to be taken into account as an additional control of $\mathrm{Fe}$ (III) reduction. Because dissolved organic matter is present in almost all natural environments such as lakes, wetlands, and soils, the occurrence of mineral-bound organic matter on $\mathrm{Fe}$ oxides is more likely than that of pure $\mathrm{Fe}$ oxides surfaces. Since the precipitation of ferrihydrite usually takes place from organic matter-containing solutions, the occurrence of coprecipitates is also more likely than that of ferrihydrite with only adsorbed organic matter. For these coprecipitates, a smaller crystal size and a more defective structure must be considered to result in faster reaction rates than compared to ferrihydrites with similar amounts of adsorbed organic matter.

Geobacteraceae have been studied intensively and are thought to contribute significantly to $\mathrm{Fe}(\mathrm{III})$ reduction in most soils and sediments (Lovley, 2011 and ref. therein). Therefore, we believe the findings of this study might 
contribute to a better understanding of processes occurring in a wide variety of environments.

\subsection{Mineral transformation during microbial reduction}

Investigating the solid remnants after 52 days of microbial reduction revealed that the formation of secondary minerals has been affected by the presence of mineral-bound organic matter (Table 2). Besides salts, such as halite, sal ammoniac and nahcolite, originating from the medium, we detected the neo-formation of goethite $(\mathrm{FeOOH})$ and siderite $\left(\mathrm{FeCO}_{3}\right)$. Siderite was found after reduction of pure ferrihydrite (Fh) and in samples with rather low amounts of organic matter (AFhA, CFhA, and CFhB), goethite was only found after reduction of the pure ferrihydrite. Thus, the formation of siderite was limited to experiments with high reduction rates and high degrees of reduction, where the solubility product of siderite was likely exceeded. The formation of goethite only took place in the absence of organic matter. This is in accordance with the general observation that goethite formation is hindered by organic matter (Schwertmann, 1966; Schwertmann, 1970) and with the experiments by Henneberry et al. (2012), who reduced ferrihydrite-organic matter coprecipitates by $\mathrm{S}(-\mathrm{II})$ and $\mathrm{Fe}(\mathrm{II})$ and observed no mineral transformation as well. Shimizu et al. (2013) also found goethite only in the control experiments with pure ferrihydrite, whereas the reduction of ferrihydrite-organic matter association favored the formation of green rust and magnetite.

Goethite formation during reduction is assumed to be catalyzed by $\mathrm{Fe}(\mathrm{II})$ ions which adsorb to the Fe oxide surface (Hansel et al., 2003; Thompson et al., 2006; Yee et al., 2006). We expected a competition of $\mathrm{Fe}$ (II) with organic matter and therefore a decreased amount of goethite formation in our experiments. However, this does not explain that no goethite was formed during the reduction of ferrihydrite in presence of only a small amount of mineral-bound organic matter. Possible explanations could be the detection limit of XRD $(\sim 5 \%)$ and a full coverage of $\mathrm{Fe}(\mathrm{II})$-reactive sites on ferrihydrite (Shimizu et al., 2013). Furthermore, a preferential reaction of $\mathrm{Fe}(\mathrm{II})$ with the mineral-bound organic matter instead of the Fe oxide surface could be considered.

\subsection{Abiotic Reduction by Na-Dithionite}

During abiotic reduction with Na-dithionite (Fig. 7, Table 1), we observed highest initial reduction rates for the pure ferrihydrite and systematically decreasing reduction rates with increasing amounts of mineral-bound organic matter. Likewise, the degree of reduction after 75 min was generally decreasing with increasing organic matter. An exception is sample CFhA, for which the dissolved Fe(II) was estimated to be larger than the total Fe, which is not possible. Therefore, we did not calculate reduction rate and degree of reduction for this sample. Reduction rates and the degree of reduction again tend to be larger for coprecipitated ferrihydrite. Thus, abiotic reduction experiments displayed the same overall picture of the reactivity of the ferrihydrite-organic matter associations as the microbial reduction experiments with G. bremensis. However, reduction rates for Na-dithionite are two to three orders of magnitude larger.

The data for abiotic reduction could be well represented by the model by Christoffersen and Christoffersen (1976, Table 1). It is interesting to note that $\gamma$ the parameter describing particle shape, particle size, reactive site density, and particle heterogeneity in this model is increasing with increasing amounts of mineral-bound organic matter from 1.3 to 2.6 for coprecipitates and from 2.9 to 7.4 for ferrihydrites with adsorbed organic matter (Table 1). Reduction of pure ferrihydrite gave a $\gamma$ of 2.4. The theoretical value for ideally dissolving isotropic particles is $2 / 3$. Houben (2003) found a $\gamma$ of 1.5 for reduction of ferrihydrite with Na-dithionite; Larsen et al. (2006) reported values between 1 and 2.2 for reduction of aquifer material by ascorbic acid. Roden (2004) observed a $\gamma$ of 0.7 for synthetic ferrihydrite reduced by ascorbic acid and values between 0.8 and 1.8 for natural Fe oxides. Reducing the same material microbially by Shewanella led to much higher values of $\gamma$ of 5.8 to 11.8. Likewise, he observed lower degrees of reduction for microbial reduction than for reduction by ascorbic acid. He concluded that the low degrees of reduction as well as the high values for $\gamma$ during microbial reduction reflect "the inhibitory effect of $\mathrm{Fe}$ (II) accumulation on enzymatic electron transfer" (Roden, 2004). However, because we observed high $\gamma$ values for abiotic reduction (Table 1), we propose that surface passivation by organic matter leads to a high $\gamma$, also.

\subsection{Summary and environmental implications}

In the present study mineral-bound soil organic matter has been shown to decrease microbial reduction by $G$. bremensis and abiotic reduction by Na-dithionite of ferrihydrite. The reactivity of ferrihydrites with adsorbed organic matter differed from ferrihydrites coprecipitated with organic matter: at similar organic matter contents higher initial reaction rates and higher degrees of reduction were observed for coprecipitated ferrihydrites. Their higher reactivity can be explained by the smaller crystal size and higher number of crystal defects due to poisoning of crystal growth in the presence of organic matter during coprecipitation. However, other aspects such as a different composition of the associated organic matter and/or a different aggregate structure may also influence reduction kinetics. At low concentrations of coprecipitated organic matter these effects may be stronger than the surface passivation by the mineral-bound organic matter and lead to an even faster reduction of coprecipitates than of pure ferrihydrite. We therefore propose that, in addition to the accumulation of $\mathrm{Fe}(\mathrm{II})$, the organic matter coverage of Fe oxide surfaces is discussed as a further widespread mechanism to slow down or cease enzymatic reduction. 
Table 2. Mineral identification by XRD after reduction by G. bremensis. Sal ammoniac $\left(\mathrm{NH}_{4} \mathrm{Cl}\right)$ is abbreviated by "sal", nahcolite $(\mathrm{NaHCO} 3)$ by "nahc".

\begin{tabular}{llcccccc}
\hline & & Halite & Sal & Nahc & Calcite & Siderite & Goethite \\
\hline Control & Fh & $\times$ & $\times$ & $\times$ & $\times$ & $\times$ & $\times$ \\
\hline \multirow{3}{*}{ Adsorbed OM } & AFhA & $\times$ & & & & $\times$ & \\
& AFhB & $\times$ & $(\times)^{\mathrm{a}}$ & & & & \\
& AFhD & $\times$ & $\times$ & & & & \\
\multirow{4}{*}{ Coprecipitated OM } & KFhA & $\times$ & $\times$ & & & $\times$ & \\
& KFhB & $\times$ & $\times$ & $\times$ & & $\times$ & \\
& KFhD & $\times$ & $\times$ & & & & \\
\hline
\end{tabular}

a $(x)$ less than three peaks identified.

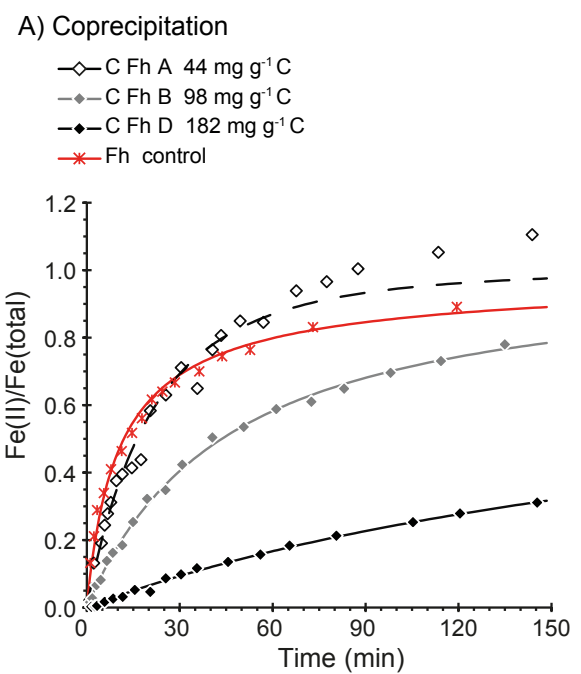

\section{B) Adsorption}

- - A Fh A $44 \mathrm{mg} \mathrm{g}^{-1} \mathrm{C}$

-.A Fh B $105 \mathrm{mg} \mathrm{g}$-C

-•-A Fh D $181 \mathrm{mg} \mathrm{g}^{-1} \mathrm{C}$

*-Fh control

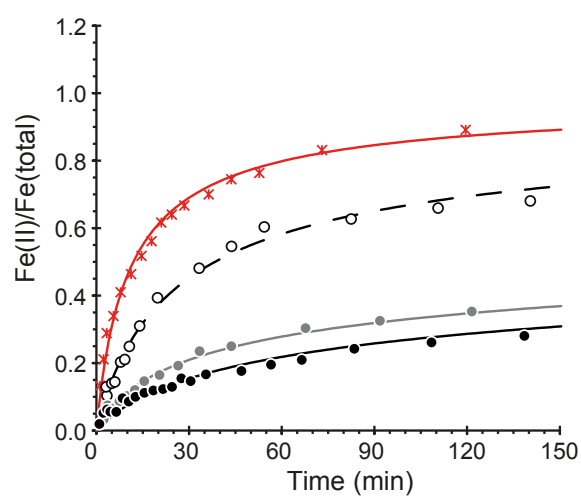

Figure 7. Abiotic reduction with Na-dithionite: Fe(II) production (normalized to the total initial Fe in ferrihydrite) versus time. Lines represent the model by Christoffersen and Christoffersen (1976). Note that the dissolved Fe(II) was estimated to be larger than the total Fe for sample CFhA, which is unreasonable.

The secondary formation of $\mathrm{Fe}$ minerals resulting from microbial reduction was also influenced by the amount of mineral-bound organic matter. Goethite was only found after reduction of the organic matter-free ferrihydrite and siderite was only detected when ferrihydrites with relatively low amounts of mineral-bound organic matter were reduced. For example, for soils, where we assume that an organic matter covered $\mathrm{Fe}$ oxide surface is rather the rule than the exception, we conclude that goethite and siderite formation is less likely than in typical microbial reduction experiments. Growth of new minerals will influence the cycling of $\mathrm{Fe}$ as well as of the usually associated nutrients and contaminants, because both goethite and siderite represent thermodynamically more stable sinks for the fixation of $\mathrm{Fe}$ (III) and Fe(II) than ferrihydrite and have different mineral surfaces.

Comparison to the studies of Pédrot et al. (2011) and Shimizu et al. (2013), let us assume that the electron transfer mechanism of a microorganism controls whether or not mineral-bound organic matter decreases or increases microbial reduction. Whereas Shewanella may use own redoxactive products to enhance electron shuttling, direct contact requiring Geobacter may not be able to reach the oxide surface when blocked by organic matter. If this hypothesis holds true, in natural environments, the likely presence of mineralbound organic matter on $\mathrm{Fe}$ oxide surfaces may increase or decrease $\mathrm{Fe}$ reduction, depending on the dominating types of microorganisms. On the other hand, the composition or activity of the Fe reducing microbial community might be regulated by the mean coverage of the Fe oxide surfaces. Systems with low dissolved organic matter concentrations and low organic matter loadings on Fe oxides might be favored by microorganisms requiring direct contact for reduction such as Geobacter, whereas systems with high dissolved organic matter concentrations might be ideal for electron shuttle or ligand driven microbial reduction. 


\section{Conclusions}

Fe oxides are recognized as very important mineral phases, which stabilize their mineral-bound organic matter against microbial degradation in the long term. In redoximorphic soils, it will depend on the type of reducing microorganism whether the presence of mineral-bound organic matter will inhibit dissolution of the carrier mineral and support organic matter storage at the same time. When direct electron transfer is the main mechanism for microbial $\mathrm{Fe}(\mathrm{III})$ reduction, the organic matter coverage will protect the underlying $\mathrm{Fe}$ mineral and promote its own preservation, whereas the opposite must be assumed for soils dominated by microorganisms using electron shuttles or ligands for Fe(III) reduction.

Acknowledgements. Part of this work was financially supported by the priority program SPP 1315 "Biogeochemical Interfaces in Soil" of the Deutsche Forschungsgemeinschaft (DFG). Many thanks to Angelika Kölbl, Markus Steffens, and Ingrid Kögel-Knabner (Lehrstuhl für Bodenkunde, Technische Universität München) for NMR-data and to Ralf Wagner (Chair of Materials Science, University of Jena) for XPS measurements. We also highly appreciate the help from Katy Pfeiffer, Gundula Rudolph, and Christine Götze in the laboratory.

Edited by: T. Treude

\section{References}

Abdulla, H. A. N., Minor, E. C., Dias, R. F., and Hatcher, P. G.: Changes in the compound classes of dissolved organic matter along an estuarine transect: a study using FTIR and C-13 NMR, Geochim. Cosmochim. Ac., 74, 3815-3838, 2010.

Amstaetter, K., Borch, T., and Kappler, A.: Influence of humic acid imposed changes of ferrihydrite aggregation on microbial Fe(III) reduction, Geochim. Cosmochim. Ac., 85, 326-341, 2012.

Arnarson, T. S. and Keil, R. G.: Organic-mineral interactions in marine sediments studied using density fractionation and X-ray photoelectron spectroscopy, Org. Geochem., 32, 1401-1415, 2001.

Arnold, R. G., Hoffmann, M. R., Dichristina, T. J., and Picardal, F. W.: Regulation of dissimilatory Fe(III) reduction activity in Shewanella-Putrefaciens, Appl. Environ. Microb., 56, 2811-2817, 1990.

Bigham, J. M., Fitzpatrick, R. W., and Schulze, D. G.: Iron oxides, in: Soil Mineralogy with Environmental Applications, edited by: Dixon, J. B. and Schulze, D. G., SSSA Book Ser. No. 7, Soil Science Society of America, Madison, WI, 2002.

Boesen, T. and Nielsen, L. P.: Molecular Dissection of Bacterial Nanowires, Mbio, e00270-13, doi:10.1128/mBio.00270-13, 2013.

Caccavo, F., Schamberger, P. C., Keiding, K., and Nielsen, P. H.: Role of hydrophobicity in adhesion of the dissimilatory Fe(III)reducing bacterium Shewanella alga to amorphous Fe(III) oxide, Appl. Environ. Microb., 63, 3837-3843, 1997.
Christoffersen, J. and Christoffersen, M. R.: Kinetics of dissolution of calcium-sulfate-dihydrate in water, J. Cryst. Growth, 35, 7988, 1976.

Cismasu, A. C., Michel, F. M., Tcaciuc, A. P., Tyliszczak, T., and Brown, J. G. E.: Composition and structural aspects of naturally occurring ferrihydrite, CR Geosci., 343, 210-218, 2011.

Cornell, R. M. and Schwertmann, U.: The Iron Oxides: Structure, Properties, Reactions, Occurrences and Uses, Wiley-VCH Verlagsgesellschaft, Weinheim, 2003.

Dunnivant, F. M., Schwarzenbach, R. P., and Macalady, D. L.: Reduction of substituted nitrobenzenes in aqueous-solution containing natural organic matter, Environ. Sci. Technol., 26, 2133 2141, 1992.

Ebadi, A., Mohammadzadeh, J. S. S., and Khudiev, A.: What is the correct form of BET isotherm for modeling liquid phase adsorption? Adsorption, 15, 65-73, 2009.

Eusterhues, K., Rumpel, C., and Kögel-Knabner, I.: Organomineral associations in sandy acid forest soils: importance of specific surface area, iron oxides and micropores, Eur. J. Soil Sci., 56, 753-763, 2005.

Eusterhues, K., Wagner, F. E., Häusler, W., Hanzlik, M., Knicker, H., Totsche, K. U., Kögel-Knabner, I., and Schwertmann, U.: Characterization of ferrihydrite-soil organic matter coprecipitates by X-ray diffraction and Mössbauer spectroscopy, Environ. Sci. Technol., 42, 7891-7897, 2008.

Eusterhues, K., Neidhardt, J., Hädrich, A., Küsel, K., and Totsche, K. U.: Biodegradation of ferrihydrite-associated organic matter, Biogeochemistry, doi:10.1007/s 10533-013-9943-0, 2014.

Eusterhues, K., Rennert, T., Knicker, H., Kögel-Knabner, I., Totsche, K. U., and Schwertmann, U.: Fractionation of organic matter due to reaction with ferrihydrite: coprecipitation versus adsorption, Environ. Sci. Technol., 45, 527-533, 2011.

Gorby, Y. A., Yanina, S., McLean, J. S., Rosso, K. M., Moyles, D., Dohnalkova, A., Beveridge, T. J., Chang, I. S., Kim, B. H., Kim, K. S., Culley, D. E., Reed, S. B., Romine, M. F., Saffarini, D. A., Hill, E. A., Shi, L., Elias, D. A., Kennedy, D. W., Pinchuk, G., Watanabe, K., Ishii, S. I., Logan, B., Nealson, K. H., and Fredrickson, J. K.: Electrically conductive bacterial nanowires produced by Shewanella oneidensis strain MR-1 and other microorganisms, P. Natl. Acad. Sci. USA, 103, 1135811363, 2006.

Grosvenor, A. P., Kobe, B. A., Biesinger, M. C., and McIntyre, N. S.: Investigation of multiplet splitting of $\mathrm{Fe} 2 \mathrm{p}$ XPS spectra and bonding in iron compounds, Surface Interface Anal., 36, 1564 1574, 2004.

Hansel, C. M., Benner, S. G., Neiss, J., Dohnalkova, A., Kukkadapu, R. K., and Fendorf, S.: Secondary mineralization pathways induced by dissimilatory iron reduction of ferrihydrite under advective flow, Geochim. Cosmochim. Ac., 67, 2977 2992, 2003.

Hansel, C. M., Benner, S. G., Nico, P., and Fendorf, S.: Structural constraints of ferric (hydr)oxides on dissimilatory iron reduction and the fate of Fe(II), Geochim. Cosmochim. Ac., 68, 32173229, 2004.

Henneberry, Y. K., Kraus, T. E. C., Nico, P. S., and Horwath, W. R.: Structural stability of coprecipitated natural organic matter and ferric iron under reducing conditions, Org. Geochem., 48, 8189, 2012. 
Houben, G. J.: Iron oxide incrustations in wells. Part 2: Chemical dissolution and modeling, Appl. Geochem., 18, 941-954, 2003.

Jambor, J. L. and Dutrizac, J. E.: Occurrence and constitution of natural and synthetic ferrihydrite, a widespread iron oxyhydroxide, Chem. Rev., 98, 2549-2585, 1998.

Jiang, J. and Kappler, A.: Kinetics of microbial and chemical reduction of humic substances: implications for electron shuttling, Environ. Sci. Technol., 42, 3563-3569, 2008.

Jones, A. M., Collins, R. N., Rose, J., and Waite, T. D.: The effect of silica and natural organic matter on the Fe(II)-catalysed transformation and reactivity of Fe(III) minerals, Geochim. Cosmochim. Ac., 73, 4409-4422, 2009.

Kang, S. H., Amarasiriwardena, D., and Xing, B. S.: Effect of dehydration on dicarboxylic acid coordination at goethite/water interface, Colloid Surf. A-Physicochem. Eng. Asp., 318, 275-284, 2008.

Kaiser, K. and Zech, W.: Dissolved organic matter sorption by mineral constituents of subsoil clay fractions, J. Plant Nutr. Soil Sc., $163,531-535,2000$

Kaiser, K., Mikutta, R., and Guggenberger, G.: Increased stability of organic matter sorbed to ferrihydrite and goethite on aging, Soil Sci. Soc. Am. J., 71, 711-719, 2007.

Karltun, E., Bain, D. C., Gustafsson, J. P., Mannerkoski, H., Murad, E., Wagner, U., Fraser, A. R., McHardy, W. J., and Starr, M.: Surface reactivity of poorly-ordered minerals in podzol B horizons, Geoderma, 94, 265-288, 2000.

Klüpfel, L., Keiluweit, M., Kleber, M., and Sander, M.: Redox Properties of Plant Biomass-Derived Black Carbon (Biochar), Environ. Sci. Technol., 48, 5601-5611, 2014.

Kotloski, N. J. and Gralnick, J. A.: Flavin electron shuttles dominate extracellular electron transfer by Shewanella oneidensis, Mbio, e00553, doi:10.1128/mBio.00553-12, 2013.

Kraemer, S. M.: Iron oxide dissolution and solubility in the presence of siderophores, Aquat. Sci., 66, 3-18, 2004.

Larsen, O. and Postma, D.: Kinetics of reductive bulk dissolution of lepidocrocite, ferrihydrite, and goethite, Geochim. Cosmochim. Ac., 65, 1367-1379, 2001.

Larsen, O., Postma, D., and Jakobsen, R.: The reactivity of iron oxides towards reductive dissolution with ascorbic acid in a shallow sandy aquifer - (Romo, Denmark), Geochim. Cosmochim. Ac., 70, 4827-4835, 2006.

Lies, D. P., Hernandez, M. E., Kappler, A., Mielke, R. E., Gralnick, J. A., and Newman, D. K.: Shewanella oneidensis MR-1 uses overlapping pathways for iron reduction at a distance and by direct contact under conditions relevant for biofilms, Appl. Environ. Microb., 71, 4414-4426, 2005.

Liu, C. X., Kota, S., Zachara, J. M., Fredrickson, J. K., and Brinkman, C. K.: Kinetic analysis of the bacterial reduction of goethite, Environ. Sci. Technol., 35, 2482-2490, 2001.

Lovley, D. R., Coates, J. D., BluntHarris, E. L., Phillips, E. J. P., and Woodward, J. C.: Humic substances as electron acceptors for microbial respiration, Nature, 382, 445-448, 1996.

Lovley, D. R., Ueki, T., Zhang, T., Malvankar, N. S., Shrestha, P. M., Flanagan, K. A., Aklujkar, M., Butler, J. E., Giloteaux, L., Rotaru, A.-E., Holmes, D. E., Franks, A. E., Orellana, R., Risso, C., and Nevin, K. P.: Geobacter: the microbe electric's physiology, ecology, and practical applications, in: Advances in Microbial Physiology, vol. 59, edited by: Poole, R. K., 2011.
Malvankar, N. S., Vargas, M., Nevin, K. P., Franks, A. E., Leang, C., Kim, B.-C., Inoue, K., Mester, T., Covalla, S. F., Johnson, J. P., Rotello, V. M., Tuominen, M. T., and Lovley, D. R.: Tunable metallic-like conductivity in microbial nanowire networks, Nat. Nanotechnol., 6, 573-579, 2011.

Malvankar, N. S., Tuominen, M. T., and Lovley, D. R.: Comment on "On electrical conductivity of microbial nanowires and biofilms" by Strycharz-Glaven et al. (2011), Energ. Environ. Sci., 5, 62476249, 2012.

Marsili, E., Baron, D. B., Shikhare, I. D., Coursolle, D., Gralnick, J. A., and Bond, D. R.: Shewanella secretes flavins that mediate extracellular electron transfer, P. Natl. Acad. Sci. USA, 105, 3968-3973, 2008.

McIntyre, N. S. and Zetaruk, D. G.: X-Ray Photoeleectron Spectroscopic studies of iron oxides, Anal. Chem., 49, 1521-1529, 1977.

Mikutta, C., Mikutta, R., Bonneville, S., Wagner, F., Voegelin, A., Christl, I., and Kretzschmar, R.: Synthetic coprecipitates of exopolysaccharides and ferrihydrite. Part I: Characterization, Geochim. Cosmochim. Ac., 72, 1111-1127, 2008.

Nevin, K. P. and Lovley, D. R.: Lack of production of electronshuttling compounds or solubilization of $\mathrm{Fe}(\mathrm{III})$ during reduction of insoluble Fe(III) oxide by Geobacter metallireducens, Appl. Environ. Microb., 66, 2248-2251, 2000.

Nevin, K. P. and Lovley, D. R.: Mechanisms for accessing insoluble $\mathrm{Fe}(\mathrm{III})$ oxide during dissimilatory $\mathrm{Fe}(\mathrm{III})$ reduction by Geothrix fermentans, Appl. Environ. Microb., 68, 2294-2299, 2002.

Pédrot, M., Le Boudec, A., Davranche, M., Dia, A., and Henin, O.: How does organic matter constrain the nature, size and availability of Fe nanoparticles for biological reduction? J. Colloid Interf. Sci., 359, 75-85, 2011.

Persson, P. and Axe, K.: Adsorption of oxalate and malonate at the water-goethite interface: molecular surface speciation from IR spectroscopy, Geochim. Cosmochim. Ac., 69, 541-552, 2005.

Piepenbrock, A., Schröder, C., and Kappler, A.: Electron transfer from humic substances to biogenic an abiogenic Fe(III) oxyhydroxide minerals, Environ. Sci. Technol., 48, 1656-1664, 2014.

Postma, D.: The reactivity of iron-oxides in sediments - a kinetic approach, Geochim. Cosmochim. Ac., 57, 5027-5034, 1993.

Regelink, I. C., Weng, L., Koopmans, G. F., and Van Riemsdijk, W. H.: Asymmetric flow field-flow fractionation as a new approach to analyse iron-(hydr)oxide nanoparticles in soil extracts, Geoderma, 202, 134-141, 2013.

Reguera, G., McCarthy, K. D., Mehta, T., Nicoll, J. S., Tuominen, M. T., and Lovley, D. R.: Extracellular electron transfer via microbial nanowires, Nature, 435, 1098-1101, 2005.

Roden, E. E.: Analysis of long-term bacterial vs. chemical Fe(III) oxide reduction kinetics, Geochim. Cosmochim. Ac., 68, 32053216, 2004.

Roden, E. E. and Urrutia, M. M.: Ferrous iron removal promotes microbial reduction of crystalline iron(III) oxides, Environ. Sci. Technol., 33, 2492-2492, 1999.

Roden, E. E., Kappler, A., Bauer, I., Jiang, J., Paul, A., Stoesser, R., Konishi, H., and $\mathrm{Xu}, \mathrm{H}$. F.: Extracellular electron transfer through microbial reduction of solid-phase humic substances, Nat. Geosci., 3, 417-421, 2010.

Royer, R. A., Burgos, W. D., Fisher, A. S., Jeon, B. H., Unz, R. F., and Dempsey, B. A.: Enhancement of hematite bioreduction by 
natural organic matter, Environ. Sci. Technol., 36, 2897-2904, 2002.

Schwertmann, U.: Inhibitory effect of soil organic matter on crystallization of amorphous ferric hydroxide, Nature, 212, 645-646, 1966.

Schwertmann, U.: Influence of various simple organic anions on formation of goethite and hematite from amorphous ferric hydroxide, Geoderma, 3, 207-214, 1970.

Schwertmann, U., Wagner, F., and Knicker, H.: Ferrihydrite-humic associations: magnetic hyperfine interactions, Soil Sci. Soc. Am. J., 69, 1009-1015, 2005.

Scott, D. T., McKnight, D. M., Blunt-Harris, E. L., Kolesar, S. E., and Lovley, D. R.: Quinone moieties act as electron acceptors in the reduction of humic substances by humics-reducing microorganisms, Environ. Sci. Technol., 32, 2984-2989, 1998.

Seah, M. P. and Dench, W. A.: Quantitative electron spectroscopy of surfaces: a standard data base for electron inelastic mean free paths in solids, Surf. Interface Anal., 1, 2-11, 1979.

Shimizu, M., Zhou, J., Schroeder, C., Obst, M., Kappler, A., and Borch, T.: Dissimilatory reduction and transformation of ferrihydrite-humic acid coprecipitates, Environ. Sci. Technol., 47, 13375-13384, 2013.

Straub, K. L., Hanzlik, M., and Buchholz-Cleven, B. E. E.: The use of biologically produced ferrihydrite for the isolation of novel iron-reducing bacteria, System. Appl. Microbiol., 21, 442-449, 1998.
Straub, K. L. and Buchholz-Cleven, B. E. E.: Geobacter bremensis sp. nov. and Geobacter pelophilus sp. nov., two dissimilatory ferric-iron-reducing bacteria, Int. J. Syst. Evol. Micr., 51, 18051808, 2001.

Stumm, W.: Reactivity at the mineral-water interface: Dissolution and inhibition, Colloids and Surfaces A - Physicochemical and Engineering Aspects, 120, 143-166, 1997.

Tamura, H., Goto, K., Yotsuyan T., and Nagayama, M.: Spectrophotometric determination of iron(II) with 1,10-phenanthroline in presence of large amounts of iron(III), Talanta, 21, 314-318, 1974.

Thompson, A., Chadwick, O. A., Rancourt, D. G., and Chorover, J.: Iron-oxide crystallinity increases during soil redox oscillations, Geochim. Cosmochim. Ac., 70, 1710-1727, 2006.

Tipping, E.: The adsorption of aquatic humic substances by ironoxides, Geochim. Cosmochim. Ac., 45, 191-199, 1981.

Torn, M. S., Trumbore, S. E., Chadwick, O. A., Vitousek, P. M., and Hendricks, D. M.: Mineral control of soil organic carbon storage and turnover, Nature, 389, 170-173, 1997.

von Canstein, H., Ogawa, J., Shimizu, S., and Lloyd, J. R.: Secretion of flavins by Shewanella species and their role in extracellular electron transfer, Appl. Environ. Microb., 74, 615-623, 2008.

van der Zee, C., Roberts, D. R., Rancourt, D. G., and Slomp, C. P.: Nanogoethite is the dominant reactive oxyhydroxide phase in lake and marine sediments, Geology, 31, 993-996, 2003.

Yee, N., Shaw, S., Benning, L. G., and Nguyen, T. H.: The rate of ferrihydrite transformation to goethite via the $\mathrm{Fe}(\mathrm{II})$ pathway, Am. Mineral., 91, 92-96, 2006. 